\title{
Pregnant Patient Knowledge of and Obstetric Provider Advice on Oral Health
}

\author{
Linda May ${ }^{*}$, Richard R. Suminski² ${ }^{2}$ Alison Y. Yeung ${ }^{3}$, Emily R. Linklater ${ }^{4}$, Cody Christensen ${ }^{4}$ \\ and Sara Jahnke ${ }^{5}$ \\ ${ }^{1}$ Division of Foundational Sciences and Research, East Carolina University, USA \\ ${ }^{2}$ Department of Physiology, Kansas City University of Medicine \& Biosciences, USA \\ ${ }^{3}$ Division of Surgical Sciences, East Carolina University, USA \\ ${ }^{4}$ Kansas City University of Medicine and Biosciences, USA \\ ${ }^{5}$ Institute for Biobehavioral Health Research, National Development \& Research Institutes, USA
}

Received: October 29, 2013; Accepted: January 06, 2014; Published: January 07, 2014

"Corresponding author: Linda May, Division of Foundational Sciences and Research, 1851 MacGregor Downs Rd, MS 701, East Carolina University, Greenville, NC, USA 27834, E-mail: MAYL@ECU.EDU

\begin{abstract}
Research suggests pregnant women and obstetric providers possess inadequate knowledge about dental care that leads to underutilization of perinatal dental serviceS.

Objectives: To examine the relationship between obstetric providers (OP) giving oral health advice to pregnant women and pregnant women's self-reported oral health awareness and behaviors (e.g., visiting dentist).

Methods: Surveys were completed by 237 pregnant or post partum patients and 31 OPs from 12 outpatient obstetric practices located throughout the United StateS.

Results: Only $21.8 \%$ of the patients reported receiving encouragement from their OP to see a dentist while pregnant and $44.4 \%$ were told the importance of good oral health during pregnancy. Patients who received both encouragement to see a dentist and were told about the importance of good oral health were six times (OR=6.3, $95 \% \mathrm{CI}=2.1-19.1)$ more likely to pay more attention to their oral health. These patients were also about four times (OR=4.4, 95\% CI = 1.9-10.2) more likely to have visited or planned to visit their dentist.

Conclusion: Obstetric provider advice can have a positive impact on awareness of oral health in pregnant women. Time should be afforded within obstetric curriculums to address oral health conditions in pregnant patientS. Further research should be done to determine how best to address this issue to improve oral health care throughout pregnancy.
\end{abstract}

Keywords: Pregnancy; Oral health; Dental care provider; Obstetric provider

\section{Introduction}

Pregnant women have a higher risk of gingivitis and pyogenic granuloma due primarily to the presence of local factors and hormonal changes [1,2]. Pregnancy also contributes to tumor-like growths, epulisgravidarum $(0.2 \%$ to $9.6 \%$ of pregnant patients), mouth dryness, and a reduction in tooth surface enamel (i.e., perimylolysis) [3-6]. The state of the mother's oral health impacts the health of their offspring, even prior to birth [7]. Significant associations have been reported between maternal periodontal disease and an elevated risk of low birth weight and preterm births especially in the economically disadvantaged $[3,8,9]$. Another concern is that the bacterial agent primarily responsible for the formation of dental caries, S. mutans, can be transmitted directly from mother to child after birth. In a study by $\mathrm{Li}$ and colleagues [10], 71\% of mother-child pairs shared an identical $S$. mutans genotype when assessed every three months for the first 3.5 years after delivery. Maternal oral health interventions have been shown effective for reducing the frequency of infant infections by $34 \%$ to $52 \%[11,12]$.

A number of statements and guidelines have been published emphasizing improved oral health care during pregnancy [13]. The American Dental Association (ADA) recommends pregnant women receive elective dental care during the second trimester and the first half of the third trimester [14]. In 2012, a committee of experts produced a consensus statement on providing adequate oral health care during pregnancy [15]. As illustrated in the findings of Watson and colleagues [16], formal and structured guidelines are needed for a substantial percentage of pregnant patientS. For instance, nearly half of women they queried did not acquire regular dental care, and thus significantly lacked awareness of relevant oral health issueS. In fact, 38\% either were not sure or believed women who were pregnant should not receive any oral health care during pregnancy. Recent data indicates that approximately $50 \%$ of pregnant women do not visit a dentist, even when they perceive a dental need $[17,18]$. Surprisingly, women with insurance receive less dental care when pregnant compared to when they are not pregnant $[19,20]$. Researchers have found that having resources to pay for care, access to care, comprehending the importance of oral health, and effective self- 
care practices in some manner influence periodontal disease outcomes in pregnant women as well as their offspring [21,22].

Clearly, identifying factors influencing oral health among women of child bearing years is highly warranted to reduce the prevalence and incidence of periodontal disease and avoid complicationS. Although relationships between characteristics of pregnant women and seeking dental care have been fairly well investigated, few studies have probed how obstetric providers fit into the equation. Some evidence suggests that patients and obstetric providers possess inadequate levels of knowledge about dental care that leads to underutilization of perinatal dental services [23-26]. However, only one of these studies included health care providers other than general dentists and the one study involving obstetric providers did not examine their role in oral health care among pregnant patients [24]. Therefore, to address this gap, the current study was performed to assess the association between oral health awareness and behavior during pregnancy with the advice from obstetric providerS. We hypothesized that obstetric provider discussion of oral health issues during pregnancy would increase their patients oral health awareness and behavior during pregnancy. In addition, we assessed obstetric provider's self-reported rates of providing oral health care advice to their pregnant patients and their desire for additional knowledge on oral health. Our approach is unique by survey pregnant patients as well as their health care provider related to oral health issueS.

\section{Methods}

\section{Study design and sample}

Questionnaires were sent to 52 U.S., medical centers randomly selected from a pool of obstetric-gynecology clinics with at least one physician alumnus from the medical school where this study was conducted. Each clinic received a packet containing patient and obstetric provider questionnaires with instructions and anonymous self-addressed return envelope $S$. The instructions described the research, explained how to complete the questionnaires, and included the contact information of the investigatorS. Twenty-five qualified female patients per clinic were randomly selected to participate in the questionnaire by a receptionist at the clinic. To qualify, a patient had to be 18 years or older and either pregnant or have given birth in the last year. The randomization protocol was distributed with the questionnaires and consisted of a simple, randomized selection scheme (ask the third pregnant patient, then fifth, etc.). The obstetric provider questionnaires could be completed by any obstetric provider in the clinic who was licensed to examine and had direct contact with pregnant patient $S$.

As appropriate, clinics received two follow-up letters to encourage the return of completed questionnaireS. Three of the clinics reported they were no longer in business and questionnaires were received from 12 of the remaining 49 clinics $(24.5 \%$ clinic-level response rate).A total of 237 patients [79\% (237/300) of patients asked to complete surveys] and 31 of their obstetric providers $(51.7 \%(31 / 66)$ of eligible obstetric providers working at the 12 clinics) completed and returned questionnaireS. All experimental procedures were approved by the University's institutional review board for the protection of human subjects, conducted in full accordance with ethical principles established by the World Medical Association Declaration of Helsinki (version 2008), and undertaken with the understanding and written consent of each participant.

\section{Measures}

Survey development: Based on previous research assessing behaviors of pregnant patients and health care provider interactions with their patients, a 25 -item patient questionnaire and an 18-item obstetric provider questionnaire were developed $[25,26]$. Content validities of the questionnaires were established a priori through two-stage expert panel reviewS. Panel members reviewed each item and proposed revisions in the first stage. Secondly, panel members reached consensus on proposed item revisionS. In order to ensure the questions were clear and concise, preliminary versions of the questionnaires were pilot-tested with a cohort of pregnant women and obstetric providerS. Reliability of the surveys was established via a test-retest pilot using the same cohort of pregnant women and obstetric providers with an alpha $>0.70$ as acceptable.

Patient survey: Part one of the survey included questions about the patient (age, level of education, marital status, race/ ethnicity, type of insurance) and their pregnancy experiences (trimester, number of previous pregnancies, number of clinic visits). In part two, patients were asked if their obstetric provider: "Encouraged me to see my dentist" or "Discussed the importance of oral health". In addition, patients were instructed to indicate their personal behavioral changes about various health habits related to pregnancy including: "During your pregnancy have you done any of the following: "Paid more attention to your oral health" and "Been to or plan to visit a dentist." In order to mask the primary intent of the oral health questions, patients were also asked in a similar fashion about behaviors related to alcohol, drug, and tobacco use. Response options for part two questions were yes or no.

Obstetric provider survey: Questions on the first part of the survey included job title, age, gender, ethnicity, number of years in practice, number of pregnant patients attended to per month, percentage of pregnant patients seen with complications, and the percentage of their patients with insurance (i.e. Medicaid, private). In the second part, obstetric providers were instructed to indicate "How often do you discuss oral health with your patients", "How often do you assist in modifying behavior related to oral health", and "Would you be interested in additional training in oral health patient education". The same questions were asked for alcohol, drug, and tobacco counseling. Responses were selected from the following scale: $1=$ always, $2=$ very frequently, 3 = frequently, $4=$ sometimes, 5 = infrequently, $6=$ very infrequently, and $7=$ never.

\section{Statistical analysis}

Descriptive statistics were calculated for each of the questionS. Next, logistic models were used to examine predictors of patients' attention to oral health and intentions to visit the dentist. First, 
patient demographics, including age, education, insurance, and race/ethnicity were entered into the model as predictorS. Age was included as a continuous variable, education was stratified as "high school degree or less" verses "more than a high school degree", insurance status was stratified as either private or Medicaid/no insurance, and race/ethnicity was dichotomized to be white versus minority. Oral health intervention was stratified into three categories and entered in the second step: (1) those who did not receive encouragement from their obstetric provider to see a dentist and did not receive information from their obstetric provider about oral health (2) those who received either encouragement to see their dentist or had their obstetric providers discuss oral health but not both (3) those who received both encouragement from their obstetric provider to see a dentist and had their obstetric provider discuss oral health with them. The 95\% confidence intervals were computed for the logistic regression model $S$. The significance level was set at $\alpha<0.05$ and all analyses were conducted using the SPSS statistical software package (SPSS for Windows, Rel. 20.0. 2011. Chicago: SPSS Inc.).

\section{Results}

\section{Demographics}

Patient demographic data are reported in Table 1. The majority of pregnant women were white (73\%) and Black/ African American (16\%).

Pregnant women were fairly distributed as far as education background: college graduate, some college, and high school graduateS. However, the majority of patients reported having Medicaid.

Table 1 also contains demographic information on obstetric providerS. The majority of practitioners were white (94\%) and female (58\%). Additionally, there was a greater percentage of DO physicians who completed the survey. According to the obstetric providers, the percentage of patients with private insurance was greater than those with Medicaid.

\section{Patient oral health history}

When patients were asked when they last visited a dentist, $38.4 \%$ reported less than six months ago, $20.7 \%$ reported $6-12$ months ago, $21.5 \%$ reported $1-2$ years ago, and $19.4 \%$ reported longer than two yearS. Almost one-fourth of the previous dental visits were for a dental problem.

\section{Obstetric provider discussion}

According to patient reports, oral health was the least discussed health behavior (Table 2). About one-fifth (21.8\%) of patients reported their obstetric provider encouraged them to see a dentist and less than half $(44.4 \%)$ said their obstetric providerS.

Discussed the importance of good oral health. In contrast, discussion about alcohol, drug, and tobacco use occurred at higher rates (Table 3).

\begin{tabular}{|c|c|}
\hline \multicolumn{2}{|c|}{ Patients } \\
\hline Age (years) & $M=25.1 ; S D=5.8$ \\
\hline Number of pregnancy & $\mathrm{M}=2.2 ; \mathrm{SD}=1.4$ \\
\hline Week of pregnancy & $M=27.0 ; S D=9.4$ \\
\hline $\begin{array}{l}\text { Ethnicity (\%) } \\
\text { American Indian/Alaskan Native } \\
\text { Asian } \\
\text { Black/African American } \\
\text { Hispanic/Latina } \\
\text { White }\end{array}$ & $\begin{array}{c}1.7 \\
2.1 \\
15.6 \\
7.2 \\
73.4\end{array}$ \\
\hline $\begin{array}{l}\text { Education }(\%) \\
\text { Less than high school } \\
\text { High school graduate } \\
\text { Some college } \\
\text { College graduate } \\
\text { Trade school } \\
\text { Graduate school }\end{array}$ & $\begin{array}{c}15.7 \\
25.4 \\
26.7 \\
22.0 \\
6.4 \\
3.8\end{array}$ \\
\hline $\begin{array}{l}\text { Insurance (\%) } \\
\text { Private } \\
\text { Medicaid } \\
\text { No insurance }\end{array}$ & $\begin{array}{c}40.5 \\
55.9 \\
3.6\end{array}$ \\
\hline \multicolumn{2}{|c|}{ ObstetricProviders } \\
\hline Age (years) & $\mathrm{M}=40.3 ; \mathrm{SD}=11.4$ \\
\hline$\%$ Female & 58.1 \\
\hline $\begin{array}{l}\text { Ethnicity (\%) } \\
\text { Black/African American } \\
\text { Hispanic/Latina } \\
\text { White }\end{array}$ & $\begin{array}{c}3.2 \\
3.2 \\
93.5\end{array}$ \\
\hline $\begin{array}{l}\text { Title }(\%) \\
\text { DO } \\
\text { MD } \\
\text { Nurse midwife } \\
\text { Nurse practitioner } \\
\text { Other }\end{array}$ & $\begin{array}{c}58.6 \\
20.7 \\
3.4 \\
10.3 \\
6.9 \\
\end{array}$ \\
\hline $\begin{array}{l}\text { How long have you practiced Ob/Gyn } \\
\text { including residency? }\end{array}$ & $\mathrm{M}=3.7 \mathrm{y} ; \mathrm{SD}=1.5 \mathrm{y}$ \\
\hline $\begin{array}{l}\text { Approximately what percentage of your } \\
\text { patients have...(\%) } \\
\text { Private } \\
\text { Medicaid } \\
\text { No insurance }\end{array}$ & $\begin{array}{c}M=49.4 ; S D=30.5 \\
M=41.9 ; S D=27.3 \\
M=7.0 ; S D=9.1\end{array}$ \\
\hline
\end{tabular}

\section{Awareness and behavior change}

Overall, the patients reported that $70.6 \%$ paid more attention to their oral health and $50.2 \%$ reported that they had been or planned to visit the dentist during their pregnancy. Logistic regressions for both paying more attention to oral health and having been/planning to visit the dentist during pregnancy showed that no demographic variables significantly predicted either behavior (Table 4).

Less than half (44.4\%) of pregnant women said their obstetric provider either discussed the importance of good oral health or had encouraged them to see a dentist. Pregnant patients, who reported that their OP encouraged them to see a dentist, were significantly more likely $(\mathrm{OR}=2.6,95 \% \mathrm{CI}=1.10$ 5.93) to report paying more attention to their oral health during pregnancy. Those who received both interventions (discussion and encouragement from OP to see dentist) were more than six 
times $(\mathrm{OR}=6.3,95 \% \mathrm{CI}=2.05-19.11)$ more likely to pay more attention to their oral health.

\section{Obstetric provider education}

Less than $25 \%$ of obstetric providers reported interest in receiving additional training to help their patients maintain or improve pro-health behaviorS. Only about $20 \%$ indicated an interest in learning how to encourage good oral hygiene in their patientS.

\section{Discussion and Conclusions}

\section{Discussion}

A low percentage of the patients were encouraged by their obstetric provider during pregnancy to see a dentist. For those who did receive either advice about the importance of oral health or were encouraged to see a dentist during their pregnancy, there was a strong effect on pregnant patient behaviorS. Women who received one or both interventions (advice or encouragement) were significantly more likely to report focusing more on their oral health and/or visiting the dentist. This suggests that, while encouraging or discussing oral health with pregnant patients takes little time, the behavioral pay-off for patients is high. The findings of the present study are similar to other studies on associations between health care provider intervention and patient oral health behavior $[27,28]$.

Few of the obstetric providers were interested in additional

\begin{tabular}{|l|c|}
\hline $\begin{array}{l}\text { During your pregnancy, has your health care provider done any of } \\
\text { the following? }\end{array}$ \\
\hline & \% Responding YES \\
\hline Discussed the importance of good oral health & 44.4 \\
\hline Encouraged you to see a dentist & 21.8 \\
\hline Discussed tobacco use & 73.3 \\
\hline Discussed drug use & 66.8 \\
\hline Discussed alcohol use & 65.7 \\
\hline
\end{tabular}

Table 2: Patient Reported Obstetric Provider Discussion.

\begin{tabular}{|l|c|c|}
\hline \multicolumn{2}{|c|}{$\begin{array}{c}\text { How often do you DISCUSS each of the following with your } \\
\text { pregnant patients? }\end{array}$} \\
\hline \multicolumn{1}{|c|}{ Topic } & M & SD \\
\hline Oral health care & 3.9 & 1.7 \\
\hline Tobacco products & 2.4 & 1.7 \\
\hline Alcohol & 2.7 & 1.8 \\
\hline Illicit drugs & 2.3 & 1.6 \\
\hline
\end{tabular}

How often do you ASSIST each of the following with your pregnant patients?

\begin{tabular}{|l|c|c|}
\hline \multicolumn{1}{|c|}{ Topic } & M & SD \\
\hline Oral health care & 3.8 & 1.7 \\
\hline Tobacco products & 2.8 & 1.7 \\
\hline Alcohol & 3.1 & 1.8 \\
\hline Illicit drugs & 3.0 & 1.8 \\
\hline
\end{tabular}

(1) always (2) very frequently (3) frequently (4) sometimes (5) infrequently (6) very infrequently (7) never

Table 3: Obstetric Providers' Reported InterventionS.
Patients who reported they paid more attention to their oral health

\begin{tabular}{|c|c|c|}
\hline & OR & $95 \% \mathrm{CI}$ \\
\hline Age & 1.0 & $0.9-1.1$ \\
\hline $\begin{array}{l}\text { Level of education } \\
\text { High school or less (referent) } \\
\text { Some college, trade school or more }\end{array}$ & 0.5 & $0.3-1.2$ \\
\hline $\begin{array}{l}\text { Type of insurance } \\
\text { Private insurance (referent) } \\
\text { Medicaid/No insurance }\end{array}$ & 0.7 & $0.3-1.6$ \\
\hline $\begin{array}{l}\text { Ethnicity } \\
\text { White (referent) } \\
\text { Minority }\end{array}$ & 1.3 & $0.6-2.9$ \\
\hline $\begin{array}{l}\text { Level of obstetric provider intervention } \\
\text { No intervention (referent) } \\
\text { Discussed oral health or encouraged to see dentist } \\
\text { Discussed oral health AND encouraged to see dentist }\end{array}$ & $\begin{array}{l}2.6 \\
6.3\end{array}$ & $\begin{array}{c}1.1-5.9 \\
2.1-19.1\end{array}$ \\
\hline
\end{tabular}

Patients who reported they had been or plan to visit their dentist during their pregnancy

\begin{tabular}{|c|c|c|}
\hline & OR & $95 \% \mathrm{CI}$ \\
\hline Age & 1.0 & $0.9-1.1$ \\
\hline $\begin{array}{l}\text { Level of education } \\
\text { High school or less (referent) } \\
\text { Some college, trade school or more }\end{array}$ & 1.3 & $0.7-2.6$ \\
\hline $\begin{array}{l}\text { Type of insurance } \\
\text { Private insurance (referent) } \\
\text { Medicaid/No insurance }\end{array}$ & 1.1 & $0.5-2.3$ \\
\hline $\begin{array}{l}\text { Ethnicity } \\
\text { White (referent) } \\
\text { Minority }\end{array}$ & 0.8 & $0.4-1.6$ \\
\hline $\begin{array}{l}\text { Level of obstetric provider intervention } \\
\text { No intervention (referent) } \\
\text { Discussed oral health or encouraged to see dentist } \\
\text { Discussed oral health AND encouraged to see dentist }\end{array}$ & \begin{tabular}{|l}
0.7 \\
4.4
\end{tabular} & $\begin{array}{c}0.4-1.5 \\
1.9-10.2\end{array}$ \\
\hline
\end{tabular}

Table 4: Factors Associated with the Patients' Oral Health AwarenesS.

information on oral health and talking to patients about oral health. This could be due to a lack of understanding about the importance of oral health in a holistic approach to patient care or the existence of a belief that they possess the appropriate knowledge concerning oral health. For example, Tarannum et al. [29] found more general dental practitioners were aware of the association between periodontal disease and pre-term births than general medical practitioners and gynecologist $S$. Similarly, another study found dentists or health professionals with specialized training had more favorable attitudes towards pregnant women's oral health compared to obstetricians/ gynecologists and nurses [30,31]. In this study, not only were obstetric providers not aware of the specific issues related to pregnancy and oral health care, but they also reported having satisfactory oral health care knowledge, and were less likely to refer patients or use a multi professional approach [30]. This insufficiency of knowledge can have serious implications for mother and child and should be addressed at various levelS. Obstetric providers will need to be educated throughout the medical profession (i.e. medical school, CMEs, residency, etc.). Additionally, better collaborations among various types of health care providers and having various medical services available within the same clinical plaza can also improve comprehensive 
health care for the pregnant patient [32]. Nevertheless, such strategies are needed given the low percentage of patients indicating discussion of oral health by their OP. In addition, the findings with regard to provider interest in the topic of oral health care in pregnant patients are particularly disappointing given the significant effect they can have on patient behavior and outcomes in the baby.

Although half of low-risk pregnancies are likely to have periodontal disease and bacterial flora, which can be associated with poor pregnancy outcomes [33,34], our patient participants reported that oral health care was the least discussed health behavior in obstetric officeS. Unfortunately, a previous study suggests that first time pregnant patients have little oral health knowledge [35]. Furthermore, if oral health was discussed it was unlikely to be encouraged. In one of our previous studies, we noted obstetric provider that discussed one healthy behavior with their pregnant patient, there was a greater chance of them discussing other healthy behavior [36]. Although we did not assess the effects of discussing multiple behaviors on oral health counseling, we did see the greatest patient behavioral change (paying more attention to oral health) when obstetric providers discussed oral health and encouraged oral health as opposed to the obstetric provider engaging in none or just one of these activitieS. Taken in aggregate, these findings indicate that the discussion and/or encouragement by an obstetric provider to changing a particular patient behavior is essential for promoting positive behavior change. This is consistent with the literature that suggests patient contact is a strong determinant of patient behavior change [37]. It may be beneficial to assess the impact of utilizing other forms of contact to promote oral health care by pregnant patient $S$. For example: utilizing office staff or electronic technology to deliver encouragement regarding regular dental visits and proper dental care during pregnancy. Such an approach has been shown to work; however, it has not been examined as a stimulant of good oral health in pregnant patients [38].

While limits exist in the ability to generalize the findings due to the small sample size and minimal diversity, the magnitude of the findings is encouraging. For many women, particularly those who are uninsured and at highest risk for poor oral health, interfacing with an obstetric provider during pregnancy provides a unique opportunity to stress the importance of oral health behavior. Second, this study was not designed to assess the impact of health care provider instruction on actual oral health behaviors, including visits to a dentist, nor was it designed to assess oral health status and behaviors before pregnancy. Finally, since oral health has been identified as a challenge especially in low socio-economic groups, more attention should be given to this sub-group. Sub-group sample sizes and lack of adequate socio-economic information (e.g., income) in the present study precluded such an examination.

\section{Conclusion}

Our main goal was to examine the relationship between obstetric providers (OP) giving oral health advice to pregnant women and pregnant women's self-reported oral health awareness and behaviors (e.g., visiting dentist) since this comparison has not previously been done. Similar to previous research, obstetric providers possess inadequate knowledge about the import of dental care during pregnancy. As a result of this inadequacy, obstetric providers underutilized perinatal dental services, and rarely discussed or encouraged their pregnant patients about oral health care or visiting a dentist. However, if obstetric providers talk with their pregnant patients about oral health, then there is a high probability the patient will pay more attention to their oral health and may schedule a dental visit. Our findings have implications for obstetric providers training related to oral health in their pregnant patientS. The results of the present study suggest some possibilities for further research to improve the oral health of pregnant women. For instance, exploring different collaboration between obstetric and dental care provider interventions, the specific components of the interventions, and their cost-effectiveness could help in the development of new protocols in prenatal office visits and increase the effectiveness of educational efforts to improve oral health during pregnancy.

\section{References}

1. Laine MA (2002) Effect of pregnancy on periodontal and dental health. Acta Odontol Scand. 60(5):257-64.

2. Raber-Durlacher JE, van Steenbergen TJ, Van der Velden U, de Graaff J, Abraham-Inpijn L (1994) Experimental gingivitis during pregnancy and post-partum: Clinical, endocrinological, and microbiological aspectS. J Clin Periodontol 21(8):549-58.

3. California Dental Association Foundation. Oral health during pregnancy and early childhood. Evidence-based guidelines for health professionals, 2010. Accessed December 10, 2012.

4. Arafat A (1974) The prevalence of pyogenic granuloma in pregnant women. J Baltimore Coll Dent Surg 29(2):64-70.

5. Steinberg BJ, Minsk L, Gluch JI, et al. (2008) Women's oral health issueS. In: Clouse AL, Sherif K, editorS. Women's health in clinical practice: a handbook for primary care. Totowa (N)): Human Press Inc; p. 273-93.

6. Pirie M, Cooke I, Linden G, C Irwin (2007) Dental manifestations of pregnancy. Obstetrician Gynaecologist 9:21-6.

7. Hale, KJ (2003) Oral Health Risk Assessment Timing and Establishment of the Dental Home. Am Acad Ped 111(5)1113-6.

8. Han YW (2011) Oral health and adverse pregnancy outcomes-What's next?. J Dent Res 90(3):289-93.

9. Xiong X, Buekens P, Fraser WD, Beck J, Offenbacher S (2006) Periodontal disease and adverse pregnancy outcomes: a systematic review. BJOG 113(2):135-43.

10. Li S, Liu T, Zhuang H (2003) Detection of the transmitted strains and non-transmitted strains of Mutans streptococci by AP-PCR. Hua Xi Kou Qiang Yi Xue ZaZhi 21(5):392-5.

11. Berkowitz RJ, Turner J, Green P (1981) Maternal Salivary Levels of Streptococcus mutans and Primary Oral Infection of InfantS. Arch Oral Biol 26(2):147-9.

12. Kohler B, Bratthall D, Krasse B (1983) Preventive Measures in Mothers Influence the Establishment of the bacterium Streptococcus mutans in their InfantS. Arch Oral Biol 28(3):225-31.

13. Buerlein J, Peabody H, Santoro K. NIHCM Foundation. Improving 
access to perinatal oral health care: strategies \& considerations for health plans: issue brief July 2010. National Institute for Health Care Management. Accessed December 10, 2012.

14. Gaffield ML, Brenda J, Colley G, Malvitz M, Romaguera R (2001) Oral Health during Pregnancy. JADA 132:1009-16.

15. Oral Health Care During Pregnancy Expert Workgroup. Oral health care during pregnancy: a national consensus statement-summary of an expert workgroup meeting. Washington, DC: National Maternal and Child Oral Health Resource Center; 2012.

16. Watson MR, Gibson G, Guo I (1998) Women's Oral Health Awareness and Care-Seeking characteristics: a pilot study. J Am Dent Assoc 129(12):1708-16.

17. Iida H, Kumar JV, Radigan AM (2009) Oral health during perinatal period in New York State. Evaluation of 2005 pregnancy risk assessment monitoring system data. N Y State Dent J 75(6):43-7.

18. Hwang SS, Smith VC, McCormick MC, Barfield WD (2011) Racial/ ethnic disparities in maternal oral health experiences in 10 states, pregnancy risk assessment monitoring system, 2004-2006.Matern Child Health J 15(6):722-9.

19.Jiang P, Bargman E P, Garrett NA, Devries A, Springman S (2008) A comparison of dental service use among commercially insured women in Minnesota before, during and after pregnancy. J Am Dent Assoc 139(9):1173-80.

20. Thoele MJ, Asche SE, Rindal DB, Fortman KK (2008) Oral health program preferences among pregnant women in a managed care organization. J Public Health Dent 68(3):174-7.

21. Machuca G, Khoshfeiz O, Lacalle JR, Machuca C, Bullon P (1999) The influence of general health and socio-cultural variables on the periodontal condition of pregnant women. J Periodontol 70(7):77985.

22. Alwaeli HA, Al-Jundi SH (2005) Periodontal disease awareness among pregnant women and its relationship with socio-demographic variableS. Int J Dent Hyg 3(2):74-82.

23. Al Habashneh R, Guthmiller JM, Levy S, Johnson GK, Squier C, et al. (2005) Factors related to utilization of dental services during pregnancy. J Clin Periodontol 32(7):815-21.

24. Strafford KE, Shellhaas C, Hade EM (2008) Provider and patient perceptions about dental care during pregnancy. J Matern Fetal Med 21(1): 63-71.

25. Boyle M, Lawrence S, Schwarte L, Samuels S, McCarthy W (2009) Health care providers' perceived role in changing environments to promote healthy eating and physical activity: baseline findings from health care providers participating in the healthy eating, active communities program. Pediatrics 123 Suppl 5: S293-S300.

26. Evenson KR, Pompeii LA (2010) Obstetrician practice patterns and recommendations for physical activity during pregnancy. J Womens Health 19(9): 1733-1740.

27. Huebner CE, Milgrom P, Conrad D, Lee RS (2009) Providing dental care to pregnant patients: a survey or Oregon general dentistS. J Am Dent Assoc 140(2): 211-222.

28. Da Costa EP, Lee JY, Rozier RG, Zeldin L (2010) Dental care for pregnant women: an assessmentof North Carolina general dentistS. J Am Dent Assoc 141(8): 986-994.

29. Tarannum F, Prasad S, Muzammil, Viviekanada L, Jayanthi D, et al. (2013) Awareness of the association between periodontal disease and pre-term births among general dentists, general medical practitioners and gynecologistS. Indian J Public Health 57(2): 92-95.

30. Alves RT, Ribeiro RA, Costa LR, Leles CR, Freire Mdo C, et al. (2012) Oral care during pregnancy: attitudes of Brazilian public health professionalS. Int J Environ Res Public Health 9(10): 3454-3464.

31. Lee RS, Milgrom P, Huebner CE, Conrad DA (2010) Dentists' perceptions of barriers to providing dental care to pregnant women. Womens Health Issues 20(5): 359-365.

32. Kloetzel MK, Huebner CE, Milgrom P (2011) Referrals for dental care during pregnancy. J Midwifery Womens Health 56(2):110-117.

33. Vogt M, Sallum AW, CeCatti JG, Morais SS (2012) Factors associated with the prevalence of periodontal disease in low-risk pregnant women. Reprod Health 9: 3.

34. Han YW (2011) Can oral bacteria cause pregnancy complications? Womens Health 7(4): 401-404.

35. Horn JM, Lee JY, Divaris K, Baker AD, Vann WF Jr (2012) Oral health literacy and knowledge among patients who are pregnant for the first time. J Am Dent. Assoc 143(9): 972-980.

36. May, LE, Suminski, RR, Glaros, A, Pyle, S, Linklater, E. Healthcare Provider Encouragement and Maternal Exercise during Pregnancy. JAOA (in press).

37. Dennis S, Williams A, Taggart J, Newall A, Denney-Wilson E, et al. (2012) Which providers can bridge the health literacy gap in lifestyle risk factor modification education: a systematic review and narrative synthesiS. BMC Family Practice13: 44-73.

38. Leijon M, Arvidsson D, Nilsen P, Stark Ekman D, Carlfjord S, et al. (2011) Improvement of physical activity by a kiosk-based electronic screening and brief intervention in routine primary health care: Patient-Initiated Versus Staff-Referred. J Med Internet Res 13(4). 